\title{
Aged garlic extract inhibits 1,2-dimethylhydrazine-induced colon tumor development by suppressing cell proliferation
}

\author{
HIROSHI JIKIHARA ${ }^{1,3}$, GUANGYING QI $^{2}$, KOICHIRO NOZOE ${ }^{2}$, MAYUMI HIROKAWA ${ }^{2}$, \\ HIROMI SATO $^{2}$, YUKA SUGIHARA ${ }^{1}$ and FUMIO SHIMAMOTO ${ }^{1,2}$ \\ ${ }^{1}$ Program in Biological System Sciences, Prefectural University of Hiroshima; ${ }^{2}$ Department of Health Science, \\ Faculty of Human Culture Science, Prefectural University of Hiroshima, Minami-ku, Hiroshima 734-8558; \\ ${ }^{3}$ Molecular Diagnostics Division, Wakunaga Pharmaceutical Co. Ltd., Kodacho, Akitakata, Hiroshima 739-1195, Japan
}

Received September 20, 2014; Accepted November 13, 2014

DOI: $10.3892 /$ or.2014.3705

\begin{abstract}
Garlic and its constituents are reported to have a preventive effect against colorectal cancer in animal models. Aged garlic extract (AGE), which is produced by natural extraction from fresh garlic for more than 10 months in aqueous ethanol, also has reputed chemopreventive effects on colon carcinogenesis, but has never been studied for its effects on colon cancer development. We investigated the antitumor effects of AGE in rats with 1,2-dimethylhydrazine (DMH)-induced carcinogenesis, and the mechanism of AGE in human colon cancer cell proliferation. F344 rats randomly divided into three groups were administered DMH $(20 \mathrm{mg} / \mathrm{kg}$ weight) subcutaneously once a week for 8 weeks in a basal diet. After the last injection, one group of rats was then moved onto a basal diet containing $3 \% \mathrm{wt} / \mathrm{wt} \mathrm{AGE}$, and rats were sacrificed at 8 or 31 weeks. The number of aberrant crypt foci (ACF), histological type of tumor and proliferative activity of the tumor lesions were analyzed by macroscopic, pathological and immunohistochemical methods. DLD-1 human colon cancer cells were utilized to investigate the effect of AGE on anti-cell proliferation. AGE decreased the number of ACF but had no effect on gross tumor pathology. AGE showed a lower number of adenoma and adenocarcinoma lesions by histological analysis. Immunohistochemical staining indicated that AGE suppressed the proliferative activity in adenoma and adenocarcinoma lesions, but showed no effect on normal colon mucosa. Moreover, we demonstrated that AGE delayed cell cycle progression by downregulating cyclin $\mathrm{B} 1$ and cdk1 expression via inactivation of NF- $\mathrm{KB}$ in the human colorectal cancer cells but did not induce apoptosis. These findings
\end{abstract}

Correspondence to: Professor Fumio Shimamoto, Department of Health Sciences, Faculty of Human Culture and Science, Prefectural University of Hiroshima, 1-1-71 Ujina-Higashi, Minami-ku, Hiroshima 734-8558, Japan

E-mail: simamoto@pu-hiroshima.ac.jp

Key words: aged garlic extract, colorectal cancer, DMH, rat, cell cycle, cyclin B1 suggest that AGE has an antitumor effect through suppression of cell proliferation.

\section{Introduction}

Garlic (Allium sativum) is widely cultivated and eaten as a food, and for thousands of years has been known to have efficacy against various diseases. Epidemiological studies have revealed that an increased intake of garlic reduces the onset risk of colon, stomach and esophageal cancer $(1,2)$. Garlic and its organosulfur components have been reported to suppress colon carcinogenesis in animal experiments (3-5) and to inhibit the proliferation of cancer cell lines in vitro (6-13). Its antitumorigenic mechanisms include inhibition of mutagenic $(14,15)$ and carcinogenic activity (16), enhancement of detoxification $(3,17)$ and protection against DNA mutagenesis (18) from activated carcinogens.

1,2-Dimethylhydrazine (DMH) is a widely used agent for the chemical inducement of colon carcinogenesis in rodents (19-21). Subcutaneously injected DMH is sequentially metabolized to methylazoxymethanol (MAM) in the liver. This metabolite is transported to the colon via the bile or blood circulation to cause DNA mutations from G:C to A:T in genes involved in cell proliferation. Following DMH treatment, the epithelial cells undergo pathogenesis from minor lesion aberrant crypt foci (ACF) to adenomas and malignant adenocarcinomas $(22,23)$.

Aged garlic extract (AGE) is a unique garlic preparation created through prolonged extraction of fresh garlic. It is less of an irritant and does not produce the uncomfortable effects of raw garlic, and is suitable for long-term use. AGE has various physiological functions, and antitumor $(24,25)$, immunostimulatory (26), anti-oxidant (27) and anti-fatigue effects (28) have been reported. Although previous studies on the effect of AGE using chemical carcinogenic agents have been evaluated, indicating its chemopreventive effect on colon carcinogenesis (29), little research has been performed on its antitumor effects and mechanisms. AGE activates phase II enzymes such as glutathione S-transferase (GST), which has been shown to decrease DNA adduct formation by detoxifying reactive metabolites, resulting in decreases in DMH-induced colon carcinogenesis. In the present study, we investigated the antitumor development 
effects of AGE in rats that had undergone DMH-induced colon carcinogenesis, and attempted to elucidate its mechanism of action by focusing on its anti-proliferative activity and induction of apoptosis.

Herein, we demonstrated that AGE inhibited DMH-induced colorectal tumor development by attenuating the proliferative activity of adenoma and adenocarcinoma cells. This suppressive effect was associated with cell cycle delay at the G2/M phase resulting from cyclin $\mathrm{B} 1$ and cdk1 downregulation, but not due to the induction of apoptosis or cell cycle arrest.

\section{Materials and methods}

Animals and diet. Four-week-old male F344 rats were purchased from Charles River Japan (Kanagawa, Japan) and maintained under controlled temperature $\left(23 \pm 2^{\circ} \mathrm{C}\right)$, humidity $(50 \pm 5 \%)$ and lighting (12 h light/dark cycle) conditions. All animal studies were approved by the Animal Care Committee of Prefectural University of Hiroshima. Animals were allowed to acclimatize for one week before the experiments were commenced, and were given free access to diet and tap water ad libitum. AGE provided by Wakunaga Pharmaceutical Co. Ltd. (Hiroshima, Japan) was produced as follows: garlic cloves were sliced and soaked in a water-ethanol mixture solution and naturally extracted for $>10$ months at room temperature $(26,27)$. The extract was evaporated until dry and mixed with basal MF diet (Oriental Yeast Co., Tokyo, Japan) at a concentration of 3\% wt/wt. 1,2-Dimethylhydrazine (DMH) was purchased from Tokyo Chemical Industry (Tokyo, Japan).

Carcinogenesis protocol. DMH was weighed and dissolved in saline, and the $\mathrm{pH}$ was adjusted to 6.5 with $\mathrm{NaHCO}_{3}$. The experimental protocol is shown in Fig. 1. A total of 25 rats were randomly distributed into three groups. The rats in group 1 $(\mathrm{n}=10)$ were fed a basal diet ad libitum throughout the experimental period and received subcutaneous injections of DMH at a dose of $20 \mathrm{mg} / \mathrm{kg}$ body weight once a week for the first 8 weeks. Group $2(n=10)$ rats received the same course of $D M H$ injections as group 1 and were fed a basal diet ad libitum. One week after the last injection of $\mathrm{DMH}$, the rats of group 2 were fed a diet containing 3\% AGE for the remaining experimental period. Group $3(n=5)$ rats received the same course of DMH injections as group 1 . The food intake and body weight of the rats were recorded weekly. Group 1 and 2 rats were sacrificed at the end of 31 weeks and group 3 rats at the end of 8 weeks, whereupon the weights of livers, spleens, kidneys and epididymal adipose tissue were measured. The entire colon was removed, cut open along the longitudinal axis from the cecum to the anus, and placed on a paper towel. Gross tumor number, size and macroscopic futures were determined, and the colon tissue was fixed in 10\% phosphate-buffered formalin for at least $24 \mathrm{~h}$ prior to pathological examination.

Analysis of aberrant crypts. Fixed colon tissue was stained with $0.5 \%$ methylene blue in distilled water for 5-15 min, and placed luminal side up on a light microscope slide. The stained whole mount colons were viewed under a microscope at a magnification of $\mathrm{x} 10$, and $\mathrm{ACF}$ were distinguished from the surrounding normal-appearing crypts by their large and ellip-

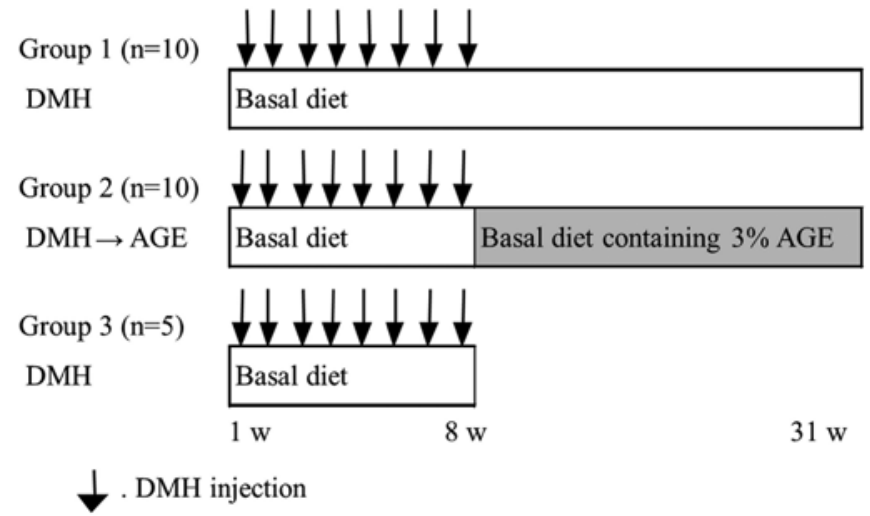

Figure 1. Experimental design. Group 1 rats were administered subcutaneous injections of $20 \mathrm{mg} / \mathrm{kg}$ body weight DMH once a week for 8 weeks and fed a basal diet throughout the experimental period. Group 2 rats were administered DMH similarly to group 1, and were fed a diet containing 3\% AGE from one week after the last injection of DMH for the remaining experimental period. Group 1 and 2 rats were sacrificed after 31 weeks. Group 3 rats were administered DMH as in group 1 and were sacrificed after 8 weeks.

tical luminal openings (30). The number of ACF with more than four crypts/focus in each colon was counted and divided by the total number of ACF to evaluate the crypt multiplicity.

Histological analysis. After ACF counting, the colons were sectioned into eight parts, which were then divided into three in the longitudinal axis direction, and dehydrated and embedded in paraffin wax. For pathological analysis, $4-\mu \mathrm{m}$ sections of formalin-fixed paraffin-embedded tissues were prepared. Deparaffinized and rehydrated slides were stained by hematoxylin and eosin (H\&E), and sections were examined under a light microscope at x200 magnification (Olympus, Japan). Tumor histology was classified as adenomas and adenocarcinomas by one investigator and one pathologist under blinded conditions according to WHO criteria (31). Tumor grade and depth of invasion were analyzed based on UICC TNM classification (6th edition).

PCNA immunohistochemical staining. Tissue sections (4- $\mu \mathrm{m})$ were deparaffinized and rehydrated with PBS, and then retrieved in a microwave oven in target retrieval solution (Dako, Glostrup, Denmark) for $10 \mathrm{~min}$. Endogenous peroxidase activity was blocked with $3 \%$ hydrogen peroxidase for $10 \mathrm{~min}$ at room temperature. The sections were incubated overnight at $4^{\circ} \mathrm{C}$ with anti-PCNA antibody (clone PC10, Dako) at a 1:200 dilution. The sections were rinsed with PBS, incubated with biotinylated secondary antibody (LSAB2 System-HRP, Dako) for $60 \mathrm{~min}$ at room temperature, incubated with HRP-linked tertiary antibody and then stained with 3,3' diaminobenzidine (DAB). Finally, all sections were counterstained with hematoxylin. Cells with brown nuclei were considered positive. Scoring of PCNA-positive indices was evaluated using ImageJ software (NIH, Bethesda, MD, USA).

Cell culture and AGE treatment. DLD-1 human colon cancer cells (ATCC CCL-221) and MRC-5 human lung fibroblast cells (ATCC CCL-171) were purchased from the American Type Culture Collection (ATCC, Manassas, VA, USA). DLD-1 and MRC-5 cells were cultured in RPMI-1640 (Nakarai, Japan) 
Table I. Final body weight, mean food intake and organ weight of the rats.

\begin{tabular}{lcccccccc}
\hline & & & & \multicolumn{3}{c}{ Organ weight } \\
\cline { 6 - 8 } Group & Treatment & $\mathrm{n}$ & $\begin{array}{c}\text { Body weight at } \\
\text { 31 weeks }(\mathrm{g})\end{array}$ & $\begin{array}{c}\text { Food intake } \\
\text { (g/day/rat) }\end{array}$ & Liver $(\mathrm{g})$ & Spleen $(\mathrm{g})$ & Kidney $(\mathrm{g})$ & $\begin{array}{c}\text { Epididymal } \\
\text { adipose tissue }(\mathrm{g})\end{array}$ \\
\hline 1 & $\mathrm{DMH}$ & 10 & $401.0 \pm 8.6$ & $14.6 \pm 0.1$ & $7.87 \pm 0.21$ & $0.72 \pm 0.01$ & $1.01 \pm 0.03$ & $11.65 \pm 0.51$ \\
2 & $\mathrm{DMH} \rightarrow \mathrm{AGE}^{\mathrm{a}}$ & 10 & $381.0 \pm 7.4$ & $14.5 \pm 0.1$ & $7.62 \pm 0.22$ & $0.71 \pm 0.03$ & $1.00 \pm 0.02$ & $10.09 \pm 0.56$ \\
\hline
\end{tabular}

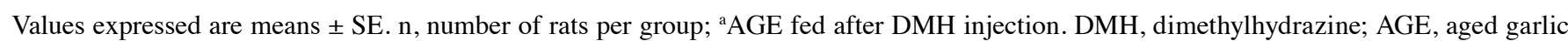
extract.

Table II. Total number and multiplicity of ACF in the colon tissue.

\begin{tabular}{lcrcccc}
\hline Group & Treatment & $\mathrm{n}$ & Weeks & Incidence (\%) & Total ACF & ACF with $>4$ AC \\
\hline 1 & DMH & 10 & 31 & 100 & $245.6 \pm 29.3$ & $50.6 \pm 10.5$ \\
2 & DMH $\rightarrow$ AGE & 10 & 31 & 100 & $178.4 \pm 25.7$ & $24.8 \pm 4.4^{\mathrm{b}}$ \\
3 & DMH & 5 & 8 & 100 & $114.2 \pm 20.8$ & $2.0 \pm 1.0$ \\
\hline
\end{tabular}

$\mathrm{n}$, number of rats per group; weeks, experimental duration. ${ }^{a}$ Number of $\mathrm{ACF}$ per rat; means $\pm \mathrm{SE} .{ }^{\mathrm{b}} \mathrm{P}<0.05$ vs. group 1 . DMH, dimethylhydrazine; AGE, aged garlic extract; ACF, aberrant crypt foci; AC, aberrant crypts.

supplemented with $10 \%$ heat-inactivated fetal bovine serum (FBS) (HyClone, Logan, UT, USA), penicillin (100 U/ml), and streptomycin $(100 \mu \mathrm{g} / \mathrm{ml})$ in a humidified atmosphere with $5 \% \mathrm{CO}_{2}$ at $37^{\circ} \mathrm{C}$. Culture media containing different concentrations of AGE were freshly prepared at the time of each experiment. When cell confluency reached 50-60\%, the cells were treated with $0,1,5$ or $10 \mathrm{mg} / \mathrm{ml}$ AGE.

Cell proliferation assay. Cells $\left(4 \times 10^{3}\right)$ were seeded in 96-well plates and incubated with different doses of AGE for varying durations, each in triplicate. After each period of incubation, cells were fixed by $50 \%$ trichloroacetic acid (TCA) at $4^{\circ} \mathrm{C}$ for $1 \mathrm{~h}$ and stained with $0.4 \%$ sulforhodamine B (Sigma-Aldrich, St. Louis, MO, USA) solution for $20 \mathrm{~min}$. The unincorporated stain was removed with $1 \%$ acetic acid. The dye was solubilized in $10 \mathrm{mM}$ Tris for $5 \mathrm{~min}$. The color reaction was quantified using a plate reader at $565 \mathrm{~nm}$.

Cell synchronization. DLD-1 cells were synchronized at the G1/S boundary by double thymidine block. The cells were presynchronized at $\mathrm{S}$ phase by incubation with $2 \mathrm{mM}$ thymidine (Wako, Japan) for $15 \mathrm{~h}$, and released by changing the medium to fresh medium without thymidine for $8 \mathrm{~h}$. Cells were then resynchronized at the $\mathrm{G} 1 / \mathrm{S}$ phase boundary by incubation with $2 \mathrm{mM}$ thymidine for $15 \mathrm{~h}$. Cells were washed and incubated in fresh medium or AGE-containing medium to promote re-entry into the cell cycle.

Cell cycle analysis. The cell cycle distribution of the DLD-1 cells was measured by flow cytometry. Cells were harvested and fixed with ice-cold $70 \%$ ethanol for $1 \mathrm{~h}$. Cells were treated with $100 \mu \mathrm{g} / \mathrm{ml}$ of RNaseA (Wako) and $25 \mu \mathrm{g} / \mathrm{ml}$ of propidium iodide (PI) (Sigma) for $30 \mathrm{~min}$ at $37^{\circ} \mathrm{C}$, and then analyzed using a FACSCalibur flow cytometer (Becton Dickinson Bioscience, Franklin Lakes, NJ, USA).

Western blotting. Cells treated with or without AGE at the indicated concentrations and times were harvested, and then resuspended in Cell-LyEX cell lysis buffer (Toyo B-Net, Japan) supplemented with Protease Phosphatase Inhibitor Cocktail (Thermo Fisher Scientific, Inc., Rockford, IL, USA) on ice for $1 \mathrm{~h}$. Whole cell lysates were centrifuged at 20,600 x g and the supernatants were used for western blotting. For the preparation of nuclear extracts, the cells were resuspended in Buffer A (10 mM HEPES (pH 7.5), 10 mM KCl, 0.1 mM EGTA, 0.1 mM EDTA, $1 \mathrm{mM}$ DTT, $0.5 \mathrm{mM}$ PMSF, proteinase inhibitors and $0.5 \%$ Nonidet P-40) on ice for $15 \mathrm{~min}$. The centrifuged pellet was resuspended in Buffer B [20 mM HEPES ( $\mathrm{pH} 7.5$ ), $400 \mathrm{mM} \mathrm{NaCl}, 1 \mathrm{mM}$ EGTA, $1 \mathrm{mM}$ EDTA, $1 \mathrm{mM}$ DTT, $1 \mathrm{mM}$ PMSF and proteinase inhibitors], and vortexed on ice for $15 \mathrm{~min}$. The centrifuged supernatant at 20,600 x g was obtained as nuclear extract protein. Equal amounts of proteins (10 or $20 \mu \mathrm{g}$ ) were boiled and separated by sodium dodecylsulfate polyacrylamide gel electrophoresis (SDS-PAGE), transferred to polyvinylidene difluoride (PVDF) membranes (Millipore, Billerica, MA, USA) and blocked with 2\% BSA $(\mathrm{w} / \mathrm{v})$ in TBST (10 mM Tris, $150 \mathrm{mM} \mathrm{NaCl}$ and $0.05 \%$ Tween20) for $1 \mathrm{~h}$ at room temperature. Membranes were incubated with primary antibodies against cyclin B1 (clone 12231), cdk1 (clone 9112), cyclin D1 (clone 2926), NF-кB p65 (clone 8242), caspase-3 (clone 9662) (Cell Signaling Technology, Beverly, MA, USA), $\beta$-actin (MBL, Japan) or lamin B1 (clone 133741, Abcam, USA) at a 1:1000 dilution at $4^{\circ} \mathrm{C}$ overnight and then incubated with horseradish peroxidase-conjugated secondary antibody (Invitrogen, Carlsbad, CA, USA) at a 1:2000 dilution at room temperature for $1 \mathrm{~h}$. Blots were visualized using 
Table III. Incidence, multiplicity and size of the gross colon tumors.

\begin{tabular}{lccccc}
\hline & & & \multicolumn{3}{c}{ Gross lesions of adenocarcinoma } \\
\cline { 4 - 6 } Group & Treatment & $\mathrm{n}$ & Incidence $(\%)$ & Multiplicity $^{\mathrm{a}}$ & Tumor diameter (mm) $^{2}$ \\
\hline 1 & DMH & 10 & 30 & $0.3 \pm 0.2$ & $7.3 \pm 1.4$ \\
2 & DMH $\rightarrow$ AGE & 10 & 30 & $0.3 \pm 0.2$ & $5.0 \pm 1.5$ \\
\hline
\end{tabular}

n, number of rats per group. ${ }^{a}$ Number of tumors per rat; means \pm SE. DMH, dimethylhydrazine; AGE, aged garlic extract.

a chemiluminescence western blotting kit (Luminate Forte Western HRP Substrate, Millipore). Analysis was performed with the ImageQuant LAS 4000 analyzer, and results were analyzed with ImageQuant TL software (GE Healthcare, Milwaukee, WI, USA).

Measurement of caspase-3 activity. DLD-1 cells $\left(4.5 \times 10^{3}\right)$ were seeded in 96-well half well plates and incubated with $0,1,5$ or $10 \mathrm{mg} / \mathrm{ml} \mathrm{AGE}$ in triplicate for 2 days; $0.05 \mu \mathrm{M}$ staurosporine (Sigma) was used as a positive control. Caspase-3 activity was measured using a commercially available Caspase-Glo 3/7 assay (Promega, Madison, WI, USA) according to the manufacturer's instructions.

Statistical analysis. The data obtained in this study are presented as means \pm standard error (SE). The significance of the differences obtained in the in vivo experiments was evaluated by unpaired two-tailed Student's t-tests. For the in vitro experiments, the statistical significance was compared between each treatment group and the control using one-way analysis of variance (ANOVA) and Tukey-Kramer's tests. A $\mathrm{P}$-value of $<0.05$ was considered significant.

\section{Results}

General observations. Throughout the study, no macroscopic abnormalities were observed in any of the groups. Body, liver, spleen, kidney, epididymal adipose tissue weights, and daily consumption of food are shown in Table I. Body and organ weight did not differ significantly in each group, nor did average food intake, indicating the long-term safety of AGE administration.

Total number and multiplicity of ACF. All rats treated with DMH for 8 weeks showed development of 114.2 \pm 20 ACF at the end of the injection course (Table II; group 3). In contrast, our previous study demonstrated that ACF were absent in DMH-untreated rats. DMH induced a total of 245.6 \pm 29 ACF per rat (group 1), while AGE intake after DMH treatment (group 2) reduced the total number of ACF $(178.4 \pm 25)$. Furthermore, the number of foci containing more than four aberrant crypts (AC)/focus was significantly decreased in group $2(24.8 \pm 4)$ compared with group $1(50.6 \pm 10)(\mathrm{P}=0.038)$ (Table II, Fig. 2B; original magnification, x10).

Effect of AGE on DMH-induced colorectal tumor development. All grossly visible tumors were semi-pedunculated, located in the middle and distal regions of the colon, and
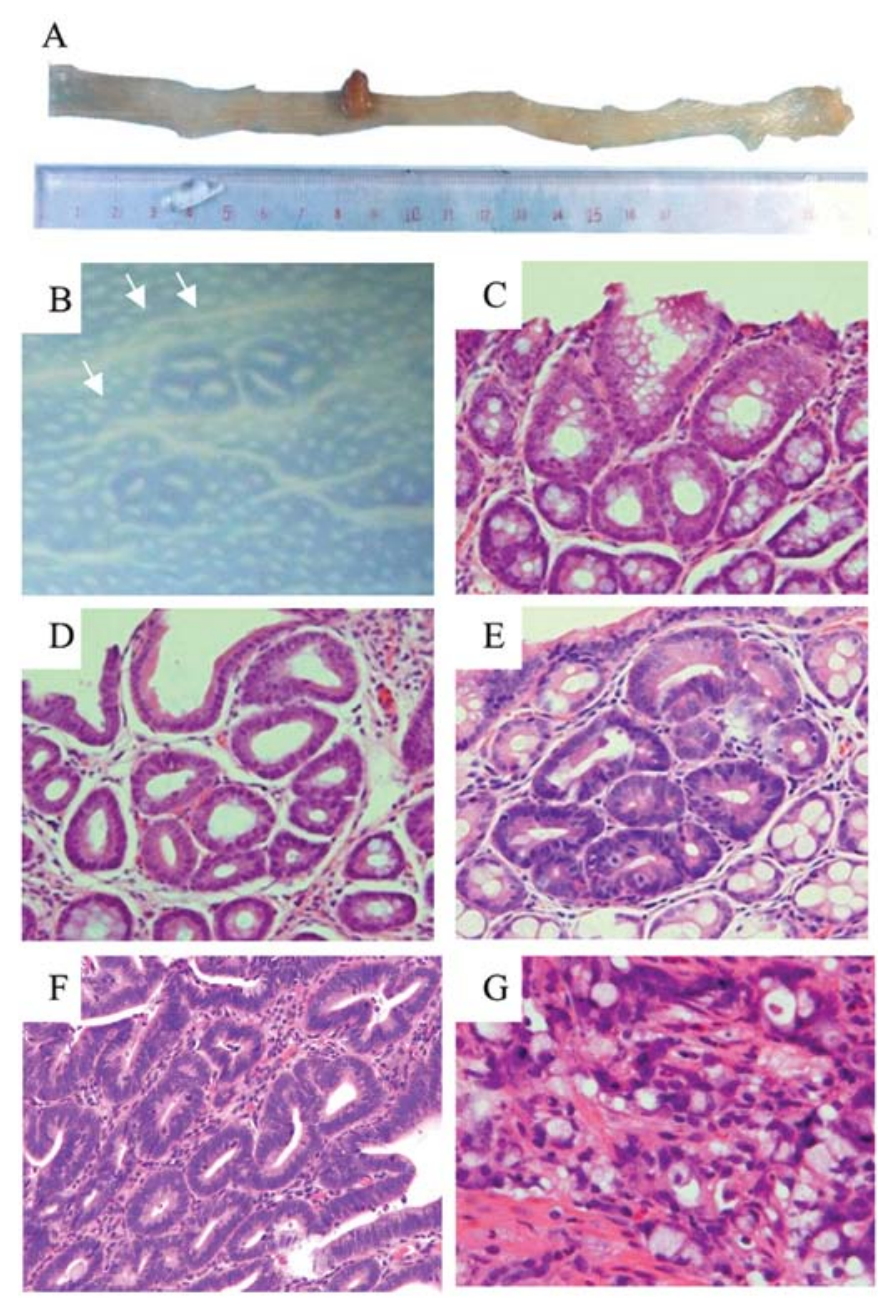

Figure 2. Macroscopic and histological features of the DMH-treated rat colon. (A) Gross features of whole colon with adenocarcinoma. (B) Colon tissues were fixed with formalin and stained with $0.5 \%$ methylene blue; whole colons showing aberrant crypt foci (ACF). Original magnification, x10. (C) Histology of adenoma with mild dysplasia. H\&E, x200. (D) Histology of adenoma with moderate dysplasia. H\&E, x200. (E) Histology of adenoma with severe dysplasia. H\&E, x200. (F) Histology of well-differentiated adenocarcinoma. H\&E, x200. (G) Histology of signet-ring cell carcinoma. $\mathrm{H} \& \mathrm{E}, \mathrm{x} 400$.

histologically diagnosed as well-differentiated adenocarcinomas (Fig. 2A and F). There were no differences in gross tumor incidence (number of rats bearing tumors per group) and multiplicity (number of tumors per rat) between group 2 and group 1. However, the mean tumor diameter of group 2 $(5.0 \pm 1.5 \mathrm{~mm})$ was smaller than group $1(7.3 \pm 1.4 \mathrm{~mm})$, but with no significant difference (Table III). On the other hand, the 
Table IV. Incidence, multiplicity and distribution of the microscopic colon adenomas.

\begin{tabular}{lcccccc}
\hline \multirow{2}{*}{ Group } & & & & \multicolumn{3}{c}{ Distribution (\%) } \\
\cline { 5 - 7 } & $\mathrm{n}$ & Incidence $(\%)$ & Multiplicity & Mild & Moderate & Severe \\
\hline 1 & 10 & 100 & $32.4 \pm 5.0$ & $62.0 \pm 4.1$ & $32.4 \pm 3.5$ & $5.6 \pm 1.4$ \\
2 & 10 & 90 & $12.5 \pm 2.7^{\mathrm{b}}$ & $76.6 \pm 6.4$ & $30.8 \pm 5.7$ & $1.6 \pm 1.1^{\text {a }}$ \\
\hline
\end{tabular}

${ }^{\mathrm{a}} \mathrm{P}<0.05,{ }^{\mathrm{b}} \mathrm{P}<0.01$, vs. group 1 .

A
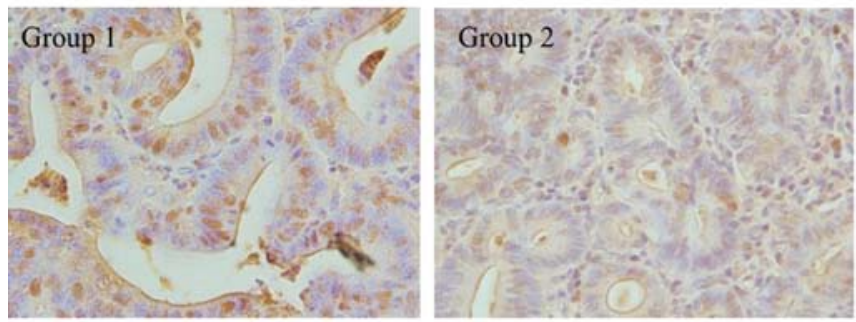

B

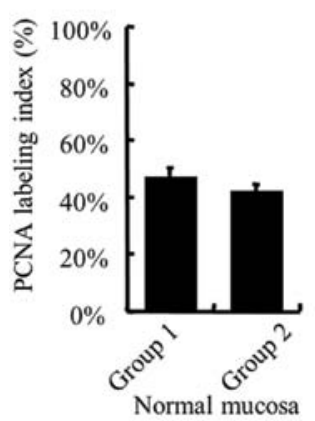

$\mathrm{C}$

D
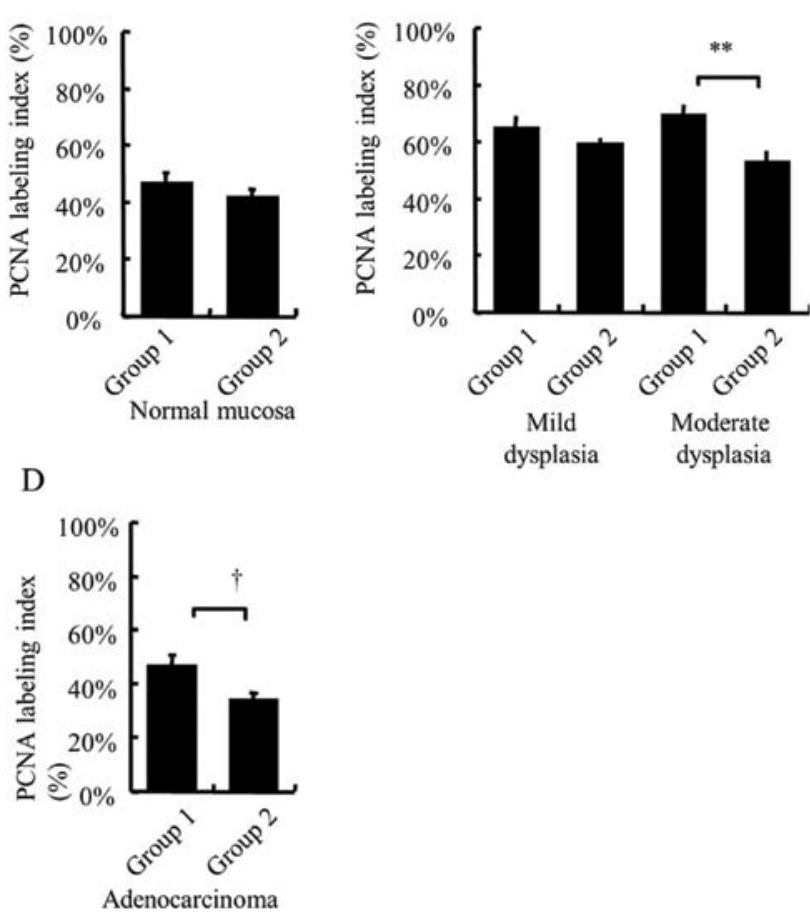

Figure 3. Effect of AGE on the proliferative activity of DMH-induced tumors (A) Photomicrographs depicting IHC staining of PCNA. Gross tumor-containing sections of colon were subjected to IHC analysis using an anti-PCNA antibody. Brown color indicates immunostaining of PCNA and light blue color indicates nuclear hematoxylin staining. Original magnification, $\mathrm{x} 400$. The percentage of cells undergoing proliferation in normal colorectal tissues (B), adenoma (C) and adenocarcinoma (D) were evaluated for PCNA labeling index using ImageJ software. Results are expressed as number of positively stained cells/total number of cells x100 in each treatment group; more than 500 cells were counted for evaluation of adenomas and adenocarcinomas Data are shown as means with standard error. ${ }^{* *} \mathrm{P}<0.01,{ }^{\dagger} \mathrm{P}=0.054$ corresponding value of group 1 .

multiplicity of microscopic tumors histologically diagnosed as adenomas in group 2 was decreased compared with group 1
$(\mathrm{P}=0.003)$ (Table IV) (Fig. 2C-E). Moreover, the percentage of adenomas with severe dysplasia was significantly reduced in group $2(\mathrm{P}=0.037)$. The pathological multiplicity of colon adenocarcinomas in group 2 and group 1 were as follows: well-differentiated adenocarcinoma, $0.2 \pm 0.1$ and $0.8 \pm 0.2$; moderately differentiated adenocarcinoma, $0.2 \pm 0.1$ and $0.3 \pm 0.1$; poorly differentiated adenocarcinoma, $0.1 \pm 0.1$ and $0.0 \pm 0.0$; mucinous adenocarcinoma was not observed; and signet-ring cell carcinoma, $0.0 \pm 0.0$ and $0.2 \pm 0.1$, respectively (Fig. 2G). The total multiplicity of adenocarcinomas in group 2 was decreased compared with group $1(0.5 \pm 0.2$ and $1.3 \pm 0.3$, $\mathrm{P}=0.078$ ). The depth of invasion of colon adenocarcinomas in group 2 and group 1 was as follows: early colorectal cancer (mucosa and submucosa), $0.5 \pm 0.2$ and 1.2 \pm 0.3 ; and advanced colorectal carcinoma (muscularis, subserosa and serosa), $0.0 \pm 0.0$ and $0.1 \pm 0.1$, respectively (Table V).

PCNA-labeling index in the colon tumor lesions. Proliferating cell nuclear antigen (PCNA) is considered to be a marker of cell proliferation, and is overexpressed in various cancers. We found that AGE decreased DMH-induced colorectal adenoma and adenocarcinoma formation. To investigate the effect of AGE on the proliferative activity of these dysplastic cells, PCNA activity in adenoma and adenocarcinoma lesions was examined by immunohistochemical (IHC) staining. Prior to IHC analysis, serial paraffin sections of colon tissues were classified as normal mucosa, adenomas or adenocarcinomas using $\mathrm{H} \& \mathrm{E}$ staining. Fig. 3A shows the proliferative activity of the grossly visible tumors diagnosed as well-differentiated adenocarcinoma lesions as measured by PCNA expression. Qualitative microscopic evaluation of the PCNA labeling index showed that it was substantially increased in group $2(\mathrm{P}=0.054)$ (Fig. 3A and D). Similarly, the PCNA labeling index in the adenoma lesions was significantly decreased in group $2(55 \pm 3 \%)$ compared with group $1(67 \pm 3 \%)(\mathrm{P}=0.005)$. Moreover, in the classification by histological type of adenomas, the AGE group showed a significantly decreased PCNA labeling index compared with the DMH group for moderate dysplasia $(53 \pm 4$ and $69 \pm 4 \%$, respectively) $(\mathrm{P}=0.01)$, but did not differ with respect to mild dysplasia $(59 \pm 2$ and $65 \pm 4 \%$, respectively) $(\mathrm{P}=0.3$; Fig. $3 \mathrm{C})$. In contrast, there was no difference in the PCNA labeling index for normal colon mucosa between the groups (Fig. 3B). These results indicate that AGE suppressed the proliferation of middle- and late-stage DMH-induced colon tumors.

Effect of AGE on the proliferation of colon cancer. To gain insight into the mechanism of tumor cell inhibition by AGE, sulforhodamine B assays were performed. DLD-1 or MRC-5 


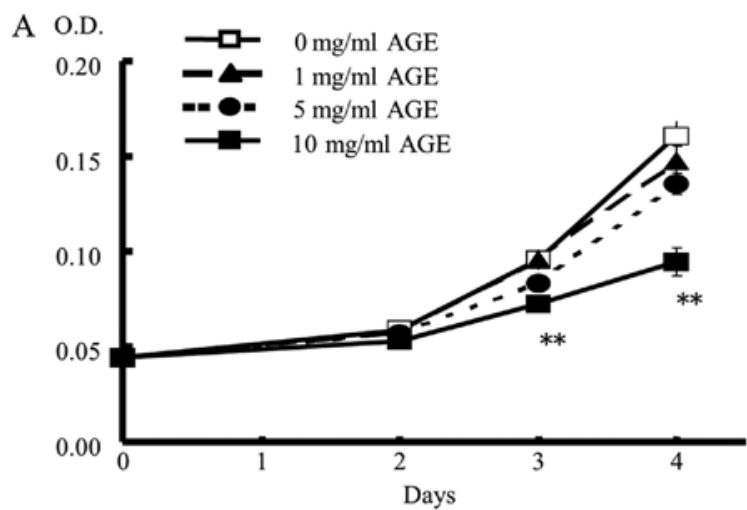

B O.D.

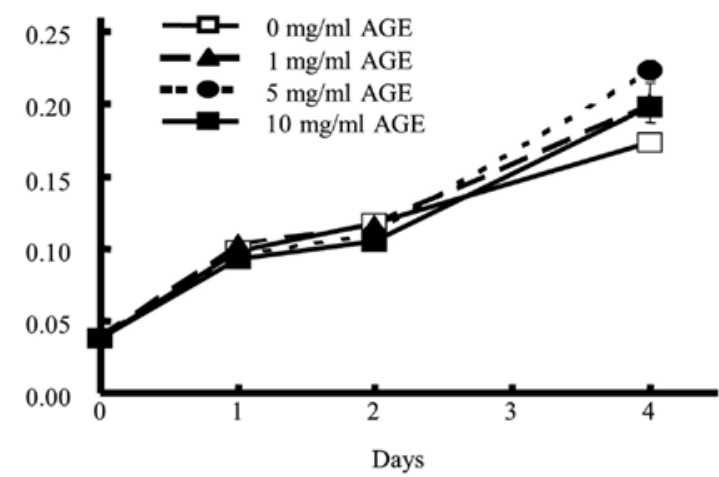

Figure 4. Effect of AGE on the proliferation of human colon cancer and fibroblast cells. Sulforhodamine B assays were performed to study the effect of AGE on DLD-1 human colon cancer cells (A) or MRC-5 fibroblast cells as the normal control (B). Cells were treated with AGE at $0,1,5$ or $10 \mathrm{mg} / \mathrm{ml}$ for different times. The cell proliferation ratio was calculated from the values obtained in the absence of AGE treatment. Data are presented as the mean \pm SE of triplicate experiments. (A) The proliferation of DLD-1 cells was significantly reduced by AGE in a dose-dependent manner over a culture period of more than 2 days. (B) AGE showed no suppressive effect on normal fibroblast MRC-5 cells.

cells were treated with AGE at different concentrations for varying durations in triplicate experiments (Fig. 4). Over a culture period of $>2$ days, DLD-1 cell proliferation was significantly suppressed by AGE in a dose- and time-dependent manner, as evidenced by statistically significant suppression at $10 \mathrm{mg} / \mathrm{ml}$ concentration compared with no AGE treatment (Fig. 4A). In contrast, AGE showed no suppressive effect on normal fibroblast MRC-5 cells under any condition (Fig. 4B).

Next, to investigate whether the growth suppressive effects of AGE were correlated with cell cycle arrest or apoptosis induction, which is a generally accepted mechanism for antiproliferative agents (32), the cell cycle distribution of DLD-1 cells was examined by flow cytometric analysis. DLD-1 cells were treated with $0,1,5$ or $10 \mathrm{mg} / \mathrm{ml}$ AGE for 2 days, and harvested cells were stained with PI. Fig. 5A and B show that AGE did not promote cell cycle arrest at any phase, and did not increase the sub-G1 population, an indicator of apoptosis. Results of the immunoblotting of whole cell lysates treated with AGE for 2 days showed that AGE did not induce the expression of cleaved caspase-3, a protein that plays a central role in the execution-phase of cell apoptosis (33) (Fig. 5C). In addition, AGE did not increase the activity of caspase-3 in the DLD-1 cells (Fig. 5D). These results indicate that the 
A

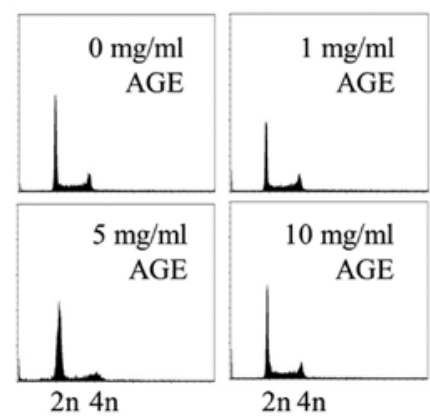

B

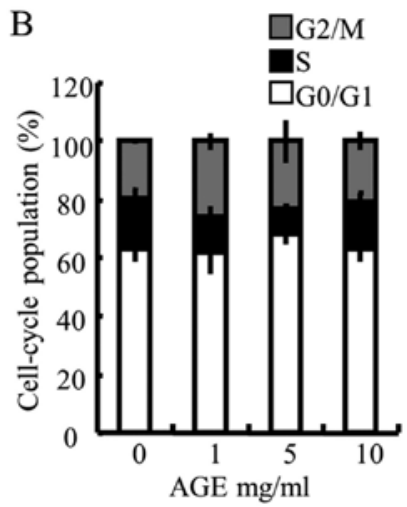

$\mathrm{C}$

DLD-1

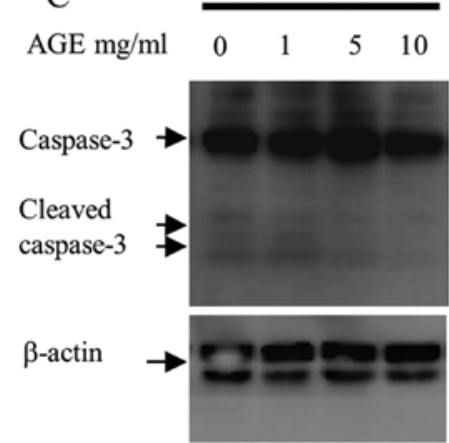

$\mathrm{D}$

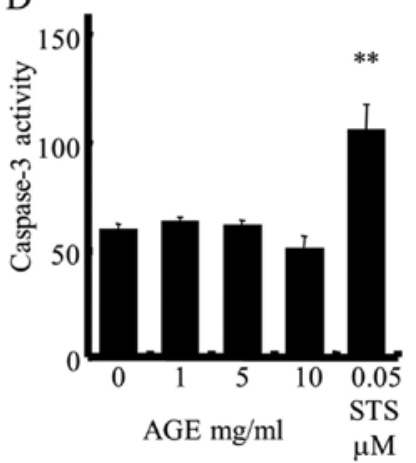

Figure 5. Effect of AGE on apoptosis of DLD-1 cells. (A) DLD-1 cells were treated with different concentrations of AGE for 2 days. Harvested cells were stained with PI and subjected to cell cycle analysis using a FACSCalibur. Representative histograms of the cell cycle distribution of DLD-1 cells are shown. (B) Analysis of the percentages of cells in G0/G1, S and G2/M phases. Data are shown as means $\pm \mathrm{SE}(\mathrm{n}=3)$. (C) Whole cell lysates of DLD-1 cells treated with AGE for 2 days were analyzed by western blotting for caspase-3 (upper panel) and $\beta$-actin (lower panel) as a loading control. The results presented are representative of three different experiments. The immunoactive bands are indicated with an arrow. (D) DLD-1 cells were treated with AGE or staurosporine (STS) $(0.05 \mu \mathrm{M})$ as a positive control for 2 days. Caspase-3 activity was assayed with the Caspase-Glo 3/7 Assay kit (Promega, USA).

anti-proliferative activity of AGE against DLD-1 cells was independent of cell cycle arrest or apoptotic cell death.

Effect of AGE on cell cycle progression. To determine whether the AGE-mediated growth suppression of colon cancer cells was related to the speed of cell cycle progression, we synchronized DLD-1 cells at the G1/S phase boundary by double thymidine block. The medium of synchronized cells was replaced with fresh culture medium with or without $10 \mathrm{mg} / \mathrm{ml}$ AGE (Fig. 6A and B). In the release medium condition, DLD-1 cells progressed into the $\mathrm{G} 2 / \mathrm{M}$ phase at $3 \mathrm{~h}$ post-release, and began to shift to the next G1 phase from the G2/M phase at $5 \mathrm{~h}$. Most cells were located in the G1 phase of the next cycle by $7 \mathrm{~h}$. The cells began to shift to the next $\mathrm{S}$ phase at $21 \mathrm{~h}$, and to shift to the next G2/M phase at $24 \mathrm{~h}$. In contrast, cells released with $10 \mathrm{mg} / \mathrm{ml}$ AGE-supplemented medium showed a cell cycle progression delay of 2-3 $\mathrm{h}$ compared with those that received release medium alone. Many cell populations were still in the G2/M phase at $5 \mathrm{~h}$ post-release. Furthermore, there were significantly more cells remaining in the $\mathrm{G} 2 / \mathrm{M}$ phase as compared with the release medium-treated cells at $9 \mathrm{~h}$. Moreover, a transition delay to the next $\mathrm{S}$ phase was confirmed in AGE-supplemented condition at 21 to $24 \mathrm{~h}$ post-release.
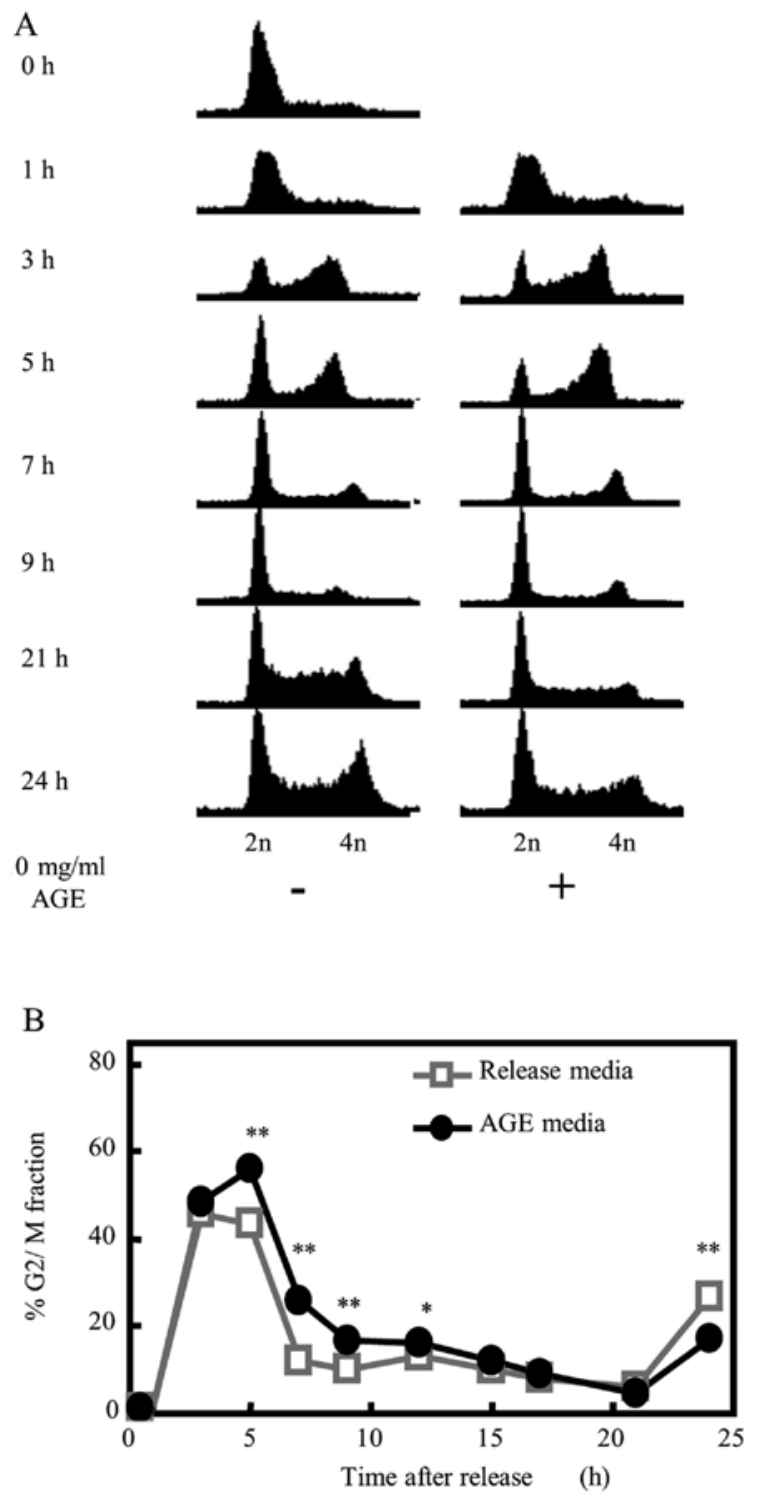

Figure 6. Effect of AGE on the cell cycle progression of DLD-1 cells. DLD-1 cells were synchronized at the G1/S boundary by double thymidine block. The synchronized cells were released by changing the medium to thymidinefree medium or $10 \mathrm{mg} / \mathrm{ml}$ AGE-supplemented medium for the indicated times. Changes in cell cycle distribution were monitored by flow cytometry. (A) Representative histogram pattern of DLD-1 cells. (B) Percentage of cells at the G2/M phase. Data are shown as means $\pm \mathrm{SE}(\mathrm{n}=3) ;{ }^{*} \mathrm{P}<0.05,{ }^{* *} \mathrm{P}<0.01$ compared with the released medium condition.

Effect of AGE on the expression levels of cell cycle-related proteins in DLD-1 cells. To investigate the mechanism of AGE-mediated proliferative inhibition based on cell cycle delay, we determined its effect on the levels of proteins related to cell cycle regulation by immunoblotting. Cyclin B1 has been reported to be an essential cell cycle component required for the transition from G2 to M phase (34-37). Cyclin-dependent kinase 1 (cdk1) forms a complex with cyclin $\mathrm{B} 1$ to regulate cell cycle progression. As shown in Fig. 7A and B, AGE treatment for 2 days caused a decrease in cyclin B1 and cdk1 protein levels in the DLD-1 cells, but did not affect the expression of cyclin D1, which is required for G1/S transition. The quantitative results demonstrated that $10 \mathrm{mg} / \mathrm{ml}$ AGE suppressed the expression of cyclin B1 and cdk1 by up to 50 and $30 \%$, respectively. In brief, AGE 
A

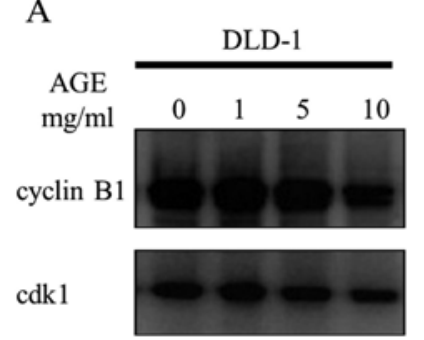

B
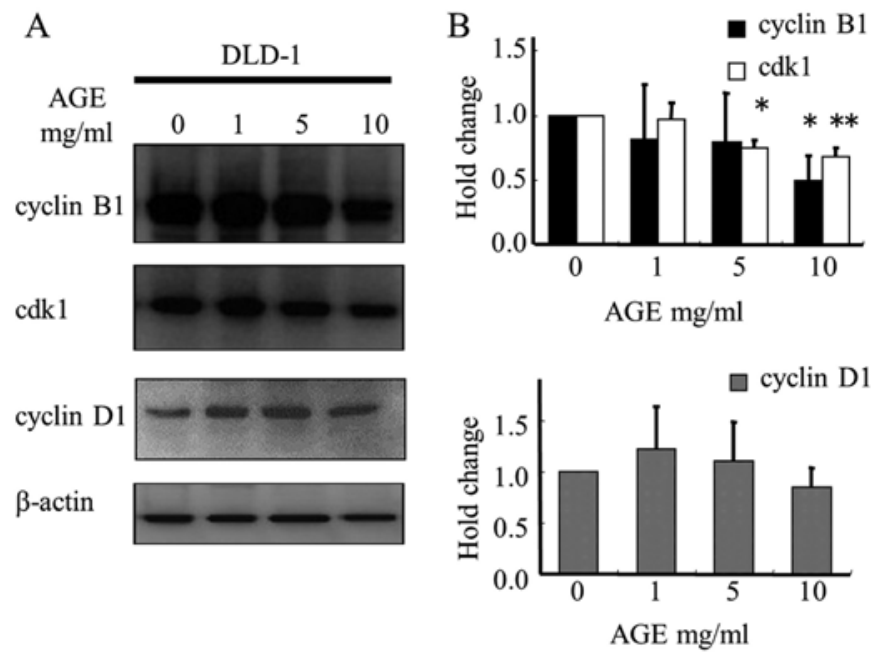

$\mathrm{C}$

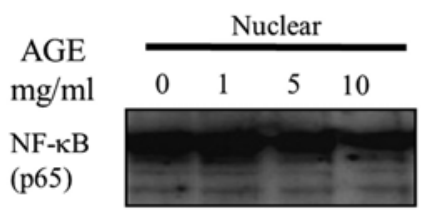

Lamin B1 $\infty$
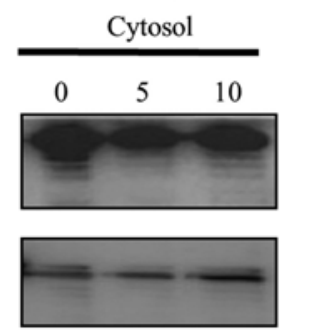

$\mathrm{D}$

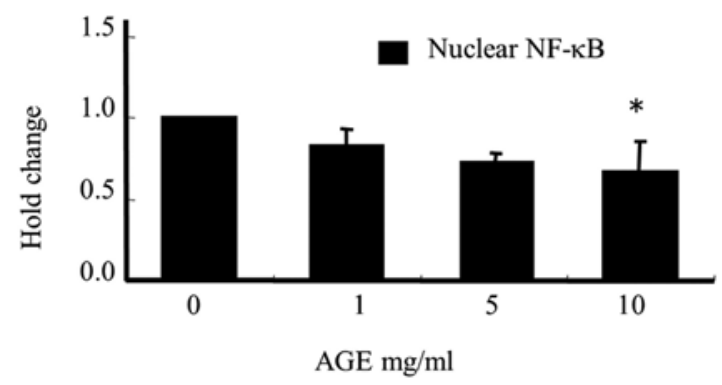

Figure 7. Effect of AGE on expression of cell cycle regulatory proteins. DLD-1 cells were treated with different concentrations $(0,1,5$ or $10 \mathrm{mg} / \mathrm{ml})$ of AGE for 2 days. (A) Equal amounts of whole cell lysates $(20 \mu \mathrm{g} / \mathrm{lane})$ were subjected to 10-20\% SDS-PAGE. Expression levels of cyclin B1, cdk1 and cyclin D1 were analyzed by western blotting. $\beta$-actin served as a positive loading control. (B) Protein expression levels of cyclin B1, cdk1 and cyclin D1 were normalized to that of $\beta$-actin and presented as the fold-change compared with the control. (C) Equal amounts of nuclear or cytosol proteins (10 $\mu \mathrm{g} /$ lane) were subjected to 10-20\% SDS-PAGE. Expression of NF- $\kappa \mathrm{B}$ (p65) was analyzed by western blotting. Lamin B1 served as a positive loading control. Each band is representative of three experiments. (D) Protein levels of nuclear NF- $\mathrm{KB}$ were normalized to that of lamin B1 and presented as the fold-change compared with the control. Data are shown as means $\pm \mathrm{SE}$ $(\mathrm{n}=3) ;{ }^{*} \mathrm{P}<0.05,{ }^{* *} \mathrm{P}<0.01$ compared with the control.

induced a cell cycle delay in DLD-1 cells by modulating the expression of regulatory proteins involved in the $\mathrm{G} 2 / \mathrm{M}$ phase cell cycle checkpoints.

Nuclear factor- $\kappa \mathrm{B}(\mathrm{NF}-\kappa \mathrm{B})$ is associated with cell proliferation, cell cycle progression and promotion of tumor growth via control of cyclin B1 expression levels $(38,39)$. To determine whether the activation of NF- $\kappa \mathrm{B}$ could be inhibited by AGE, the major component of the NF- $\kappa \mathrm{B}$ complex, p65, located in the nucleus, was assessed by immunoblotting. Western blot analysis data showed that AGE treatment significantly attenuated the translocation of p65 from the cytosol to the nucleus in a dose-dependent manner (Fig. 7C and D).

\section{Discussion}

Many studies suggest that garlic has anticancer properties. Recent studies have demonstrated several molecular mechanisms for its anti-carcinogenic effects in animal models, including its direct suppression of cancer cell proliferation and also its indirect action of inhibiting carcinogen activation by enhancing detoxification though the induction of anti-oxidant enzymes or modulation of cytochrome P450-dependent monooxygenases (40). In this study, to investigate the effect of AGE against tumor development independent of its detoxification effects on carcinogenic agents, rats were administered an AGE-containing basal diet from one week after a final DMH injection to the end of experiment, and colonic tumors were evaluated pathologically. The ultimate carcinogenic metabolite of DMH is responsible for the methylation of DNA bases in tissue including colorectal epithelial, resulting in the development of dysplastic aberrant crypts and progression to adenomas, followed by adenocarcinoma development $(19,21)$. In this experiment, ACF development was observed in all rats at the end of the DMH treatment (Table II, group 3), thus confirming that the carcinogenic initiation by this DMH treatment protocol was certainly occurring in the rat colon at the time that AGE intake was commenced; the effect of AGE on tumors was evaluated as the effect on dysplastic cells that exhibited elevated growth activity in the tumor development phase. Pretlow et al showed that aberrant crypts with high multiplicity ( $>4$ crypts/focus) correlate with tumor incidence (41). Furthermore, it is well known that the proliferative activity of dysplastic cells is elevated with the grade of tumor. AGE feeding, however, did not inhibit gross tumorigenesis, but the mean tumor diameter was decreased by AGE. It is considered that these gross tumors could have been formed by initial DMH treatment and had already developed at the time of AGE feeding. On the other hand, we demonstrated that AGE substantially reduced DMH-induced colon adenocarcinomas $(\mathrm{P}=0.07)$ and significantly reduced adenomas $(\mathrm{P}<0.01)$ and ACF with higher crypt multiplicities $(\mathrm{P}<0.05)$ (Tables II-IV). Further analysis of the histological type of adenomas revealed that AGE significantly reduced the percentage of adenomas with severe dysplasia rather than those with mild or moderate dysplasia. Our results suggest that the antitumor effect of AGE is due to its inhibitory effect on the development of these dysplastic lesions (Tables II-V).

One of the common events in tumor development is cell cycle deregulation. PCNA is known as a cell proliferation marker; the degree of PCNA expression generally correlates well with the mitotic activity of neoplastic cells and tumor grade $(42,43)$. Garlic derivative diallyl disulfide (DADS)mediated inhibition of breast cancer cell proliferation was correlated with reduced PCNA activity (44). Another garlic derivative, s-allylcysteine (SAC), inhibited PCNA protein levels in a mouse tumor xenograft model of oral cancer (45). Our experiment showed that AGE inhibited the expression of PCNA in high-grade adenoma and adenocarcinoma cells with no effect on normal colon ductal cells (Fig. 3). That is, AGE suppressed the proliferation of tumor cells in which the proliferation was abnormally enhanced. This could be due to tumor-specific suppression of proliferation by AGE; it is well known that tumor cells that proliferate much faster contain 
very high levels of PCNA compared with normal mucosa. These results indicate that the antitumor effect of AGE on the development of colonic tumors is correlated with suppression of the proliferative activity of dysplastic lesions.

We investigated the growth inhibitory mechanism of tumor cells by AGE using DLD-1 human colon cancer cells. Matsuura et al demonstrated the growth inhibitory effect of AGE against HT29, SW480 and SW620 colorectal cancer cell lines in vitro (25). We demonstrated that AGE suppressed DLD-1 proliferation but did not inhibit that of MRC-5 normal fibroblasts (Fig. 4). However, the growth inhibitory effect of AGE was gradual and the difference was observed following treatment of more than 2 days. The doubling time of cancer cells is approximately $24 \mathrm{~h}$; if agents with strong effects on apoptosis or cell cycle arrest are used, the growth inhibitory effect could be observed even after one day of incubation. This indicates that AGE does not have a strong growth inhibitory effect on cells.

The anti-carcinogenic effect of several organosulfur compounds (OSCs) derived from garlic have been reported in animal models induced by a variety of chemical carcinogens and in many cultured cancer cell lines including breast, colon, prostate, gastric and lung cancer (40). Recent studies have revealed that certain OSCs can suppress the proliferation of cancer cells by regulating cell cycle progression such as the induction of $\mathrm{G} 2 / \mathrm{M}$ phase arrest, and have also been shown to induce apoptosis via the intrinsic pathway by altering the ratio of the BCL-2 family of proteins both in cell culture and in vivo models. Caspase- 3 is a critical executioner of apoptosis, and cleavage to its active form induces apoptosis (40). However, in the present study, AGE did not induce the expression of cleaved caspase-3 in DLD-1 cells and did not promote cell cycle arrest in any specific phase (Fig. 5). Thus, the effect of AGE on growth inhibition was not due to the induction of apoptosis or cell cycle arrest. Interestingly, however, as a result of the synchronized cell cycle analysis, which was conducted to study the correlation between cell growth suppression and cell cycle progression, AGE promoted delayed cell cycle progression of 2-3 h at the $\mathrm{G} 2 / \mathrm{M}$ phase compared with normal conditions (Fig. 6), which was followed by the downregulation of cyclin B1 and cdk1 protein expression (Fig. 7).

Eukaryotic cell cycle progression involves sequential activation of cdk1 associated with cyclin B1. A complex of cyclin $\mathrm{B} 1$ and cdk1 plays a major role in regulation of the G2 to M transition (46). Ryu et al showed that the decrease in cyclin B1 and cdk1 expression was correlated with $\mathrm{G} 2 / \mathrm{M}$ arrest (47). These results suggest that AGE-mediated cell cycle delay at the G2/M checkpoint but not apoptosis induction is associated with a slight decrease in cyclin B1 and cdk1 protein levels. The cell proliferation suppressive effect of AGE in DLD-1 cells was observed at more than 2 days of treatment in a dose dependent-manner and did not cause cell death even at 4 days of treatment (Fig. 4). We showed that AGE inhibited cell proliferation slowly, without apoptosis or cell cycle arrest, and was correlated with the results obtained following a delay of 2-3 h compared with the normal cell doubling time. Delay of the cell cycle at the $\mathrm{G} 2 / \mathrm{M}$ phase caused a decrease in the population of cells in the $\mathrm{S}$ phase, and was consistent with the suppressed PCNA labeling index of colon tumor tissue from the AGE-fed rats.
$\mathrm{NF}-\kappa \mathrm{B}$ transcription factor is constitutively activated in human pancreatic, breast, prostate and lung cancer cells as well as colorectal carcinomas, which provides favorable conditions for cancer cell proliferation (10,48-51). Furthermore, NF- $\kappa \mathrm{B}$ is activated in human colon tumor lesions and adenomatous polyps (52). NF- $\kappa \mathrm{B}$ activation involves its translocation from the cytoplasm to the nucleus, where it binds to target sequences to regulate gene expression (48). NF- $\kappa \mathrm{B}$ is blocked by overexpression of the mutant form of its inhibitor, $\mathrm{I} \kappa \mathrm{B}$, which reduces $\mathrm{NF}-\kappa \mathrm{B}$ translocation to the nucleus and decreases cell survival via downregulation of cyclin B1 expression $(38,39)$. In this manner, $\mathrm{NF}-\kappa \mathrm{B}$ regulates cell proliferation by controlling cyclin B1 expression levels. Pai et al showed that SAC included in AGE was able to inhibit the activation of $N F-\kappa B$ in a mouse xenograft tumor model (45). In this study, we demonstrated that AGE reduced the amount of NF- $\kappa \mathrm{B}$ in the nuclei of DLD-1 cells (Fig. 7). That is, it can be considered that the lower expression levels of cyclin B1 and cdk1 by the action of AGE on tumor cells is associated with its reduction in $\mathrm{NF}-\kappa \mathrm{B}$ activity.

In conclusion, the results of the present study indicate that dietary administration of AGE effectively attenuated colon tumor cell progression in a rat tumor model. The possible mechanisms proposed here revealed that the antitumor effect of AGE is to delay the rate of cellular proliferation by lowering cyclin B1 and cdk1 expression levels through attenuation of $\mathrm{NF}-\kappa \mathrm{B}$ activity. To the best of our knowledge, this is the first report that AGE-mediated suppression of tumor progression is related to the downregulation of cell cycle-associated proteins. AGE is appropriate for long-term administration due to its low toxicity, and thus is suitable as a chemopreventive agent against colon tumor.

\section{Acknowledgements}

This study was supported in part by the important Research Grant from the Prefectural University of Hiroshima. The authors thank Drs Kodera and Imamura of Wakunaga Pharmaceutical Co. for the preparation of AGE, and Hiroshima Tsuchiya General Hospital for technical support.

\section{References}

1. Fleischauer AT, Poole C and Arab L: Garlic consumption and cancer prevention: meta-analyses of colorectal and stomach cancers. Am J Clin Nutr 72: 1047-1052, 2000.

2. Gao CM, Takezaki T, Ding JH, Li MS and Tajima K: Protective effect of allium vegetables against both esophageal and stomach cancer: a simultaneous case-referent study of a high-epidemic area in Jiangsu Province, China. Jpn J Cancer Res 90: 614-621, 1999.

3. Sumiyoshi $\mathrm{H}$ and Wargovich MJ: Chemoprevention of 1,2-dimethylhydrazine-induced colon cancer in mice by naturally occurring organosulfur compounds. Cancer Res 15: 5084-5087, 1990.

4. Hatono S, Jimenez A and Wargovich MJ: Chemopreventive effect of S-allylcysteine and its relationship to the detoxification enzyme glutathione S-transferase. Carcinogenesis 17: 1041-1044, 1996.

5. Wang X, Jiao F, Wang QW, et al: Aged black garlic extract induces inhibition of gastric cancer cell growth in vitro and in vivo. Mol Med Rep 5: 66-72, 2012.

6. Xiao D, Pinto JT, Soh JW, Deguchi A, et al: Induction of apoptosis by the garlic-derived compound S-allylmercaptocysteine (SAMC) is associated with microtubule depolymerization and c-Jun NH(2)-terminal kinase 1 activation. Cancer Res 63: 6825-6837, 2003. 
7. Knowles LM and Milner JA: Depressed p34 cdc2 kinase activity and $\mathrm{G} 2 / \mathrm{M}$ phase arrest induced by diallyl disulfide in HCT-15 cells. Nutr Cancer 30: 169-174, 1998.

8. Shirin H, Pinto JT, Kawabata Y, et al: Antiproliferative effects of S-allylmercaptocysteine on colon cancer cells when tested alone or in combination with sulindac sulfide. Cancer Res 61: 725-731, 2001.

9. Hosono T, Fukao T, Ogihara J, Ito Y, Shiba H, Seki T and Ariga T: Diallyl trisulfide suppresses the proliferation and induces apoptosis of human colon cancer cells through oxidative modification of beta-tubulin. J Biol Chem 280: 41487-41493, 2005.

10. Ban JO, Yuk DY, Woo KS, et al: Inhibition of cell growth and induction of apoptosis via inactivation of NF-kappaB by a sulfurcompound isolated from garlic in human colon cancer cells. $\mathrm{J}$ Pharmacol Sci 104: 374-383, 2007.

11. Sriram N, Kalayarasan S, Ashokkumar P, Sureshkumar A and Sudhandiran G: Diallyl sulfide induces apoptosis in Colo 320 DM human colon cancer cells: involvement of caspase-3, NF-kappaB, and ERK-2. Mol Cell Biochem 311: 157-165, 2008.

12. Liang D, Qin Y, Zhao W, et al: S-allylmercaptocysteine effectively inhibits the proliferation of colorectal cancer cells under in vitro and in vivo conditions. Cancer Lett 310: 69-76, 2011.

13. Dong M, Yang G, Liu H, Liu X, Lin S, Sun D and Wang Y: Aged black garlic extract inhibits HT29 colon cancer cell growth via the PI3K/Akt signaling pathway. Biomed Rep 2: 250-254, 2014.

14. Soni KB, Lahiri M, Chackradeo P, Bhide SV and Kuttan R: Protective effect of food additives on aflatoxin-induced mutagenicity and hepatocarcinogenicity. Cancer Lett 115: 129-133, 1997.

15. Knasmüller S, de Martin R, Domjan G and Szakmary A: Studies on the antimutagenic activities of garlic extract. Environ Mol Mutagen 13: 357-365, 1989.

16. Amagase $\mathrm{H}$ and Milner JA: Impact of various sources of garlic and their constituents on 7,12-dimethylbenz[a]anthracene binding to mammary cell DNA. Carcinogenesis 14: 1627-1631, 1993.

17. Sparnins VL, Barany G and Wattenberg LW: Effects of organosulfur compounds from garlic and onions on benzo[a] pyrene-induced neoplasia and glutathione S-transferase activity in the mouse. Carcinogenesis 9: 131-134, 1988.

18. Tadi PP, Tee RW and Lau BH: Organosulfur compounds of garlic modulate mutagenesis, metabolism, and DNA binding of aflatoxin B1. Nutr Cancer 15: 87-95, 1991.

19. Perše M and Cerar A: Morphological and molecular alterations in 1,2 dimethylhydrazine and azoxymethane induced colon carcinogenesis in rats. J Biomed Biotechnol 2011: 1-14, 2011.

20. Tammariello AE and Milner JA: Mouse models for unraveling the importance of diet in colon cancer prevention. J Nutr Biochem 21: 77-88, 2010.

21. Chen J and Huang XF: The signal pathways in azoxymethaneinduced colon cancer and preventive implications. Cancer Biol Ther 8: 1313-1317, 2009.

22. Takahashi M and Wakabayashi K: Gene mutations and altered gene expression in azoxymethane-induced colon carcinogenesis in rodents. Cancer Sci 95: 475-480, 2004

23. Lijinsky W, Saavedra JE and Reuber MD: Organ-specific carcinogenesis in rats by methyl- and ethylazoxyalkanes. Cancer Res 45: 76-79, 1985

24. Tanaka S, Haruma K, Kunihiro M, et al: Effects of aged garlic extract (AGE) on colorectal adenomas: a double-blinded study. Hiroshima J Med Sci 53: 39-45, 2004

25. Matsuura N, Miyamae Y, Yamane K, et al: Aged garlic extract inhibits angiogenesis and proliferation of colorectal carcinoma cells. J Nutr 136 (Suppl 3): 842-846, 2006.

26. Kyo E, Uda N, Kasuga S and Itakura Y: Immunomodulatory effects of aged garlic extract. J Nutr 131: S1075-S1079, 2006.

27. Morihara N, Sumioka I, Moriguchi T, Uda N and Kyo E: Aged garlic extract enhances production of nitric oxide. Life Sci 71: 509-517, 2002

28. Morihara N, Ushijima M, Kashimoto N, et al: Aged garlic extract ameliorates physical fatigue. Biol Pharm Bull 29: 962-966, 2006.

29. Katsuki T, Hirata K, Ishikawa H, Matsuura N, Sumi S and Itoh $\mathrm{H}$ : Aged garlic extract has chemopreventative effects on 1,2-dimethylhydrazine-induced colon tumors in rats. J Nutr 136 (Suppl 3): 847-851, 2006.

30. McLellan EA, Medline A and Bird RP: Sequential analyses of the growth and morphological characteristics of aberrant crypt foci: putative preneoplastic lesions. Cancer Res 51: 5270-5274, 1991.
31. Pindborg JJ, Reichart PA, Smith CJ and Waal I: Histological typing of cancer and precancer of the oral mucosa. 2nd edition. WHO, Geneva, pp21-31, 1997.

32. Ferreira CG, Epping M, Kruyt FA and Giaccone G: Apoptosis: target of cancer therapy. Clin Cancer Res 2002 8: 2024-2034, 2002.

33. Alnemri ES, Livingston DJ, Nicholson DW, Salvesen G, Thornberry NA, Wong WW and Yuan J: Human ICE/CED-3 protease nomenclature. Cell 87: 171, 1996.

34. Muschel RJ, Zhang HB, Iliakis G and McKenna WG: Cyclin B expression in HeLa cells during the G2 block induced by ionizing radiation. Cancer Res 51: 5113-5117, 1991.

35. Metting NF and Little JB: Transient failure to dephosphorylate the cdc2-cyclin B1 complex accompanies radiation-induced G2-phase arrest in HeLa cells. Radiat Res 143: 286-292, 1995.

36. Kao GD, McKenna WG, Maity A, Blank K and Muschel RJ: Cyclin B1 availability is a rate-limiting component of the radiation-induced G2 delay in HeLa cells. Cancer Res 57: 753-758, 1997.

37. Azzam EI, de Toledo SM, Gooding T and Little JB: Intercellular communication is involved in the bystander regulation of gene expression in human cells exposed to very low fluences of alpha particles. Radiat Res 150: 497-504, 1998.

38. Guo G, Yan-Sanders Y, Lyn-Cook BD, et al: Manganese superoxide dismutase-mediated gene expression in radiationinduced adaptive responses. Mol Cell Biol 23: 2362-2378, 2003.

39. Ozeki M, Tamae D, Hou DX, Wang T, Lebon T, Spitz DR and Li JJ: Response of cyclin B1 to ionizing radiation: regulation by NF-kappaB and mitochondrial antioxidant enzyme MnSOD Anticancer Res 24: 2657-2663, 2004.

40. Herman-Antosiewicz A, Powolny AA and Singh SV: Molecular targets of cancer chemoprevention by garlic-derived organosulfides. Acta Pharmacol Sin 28: 1355-1364, 2007.

41. Pretlow TP1, Cheyer C and O'Riordan MA: Aberrant crypt foci and colon tumors in F344 rats have similar increases in proliferative activity. Int J Cancer 56: 599-602, 1994.

42. Hur K, Kim JR, Yoon BI, Lee JK, Choi JH, Oh GT and Kim DY: Overexpression of cyclin D1 and cyclin E in 1,2-dimethylhydrazine dihydrochloride-induced rat colon carcinogenesis. J Vet Sci 1: 121-126, 2000

43. Janakiram NB, Mohammed A, Qian L, Choi CI, Steele VE and Rao CV: Chemopreventive effects of RXR-selective rexinoid bexarotene on intestinal neoplasia of Apc(Min/+) mice. Neoplasia 14: 159-168, 2012

44. Powolny AA and Singh SV: Multitargeted prevention and therapy of cancer by diallyl trisulfide and related Allium vegetablederived organosulfur compounds. Cancer Lett 269: 305-314, 2008.

45. Pai MH, Kuo YH, Chiang EP and Tang FY: S-Allylcysteine inhibits tumour progression and the epithelial-mesenchymal transition in a mouse xenograft model of oral cancer. Br J Nutr 14: 28-38, 2012.

46. Xiao D, Vogel V and Singh SV: Benzyl isothiocyanate-induced apoptosis in human breast cancer cells is initiated by reactive oxygen species and regulated by Bax and Bak. Mol Cancer Ther 5: 2931-2945, 2006.

47. Ryu DS, Kim SH and Lee DS: Anti-proliferative effect of polysaccharides from Salicornia herbacea on induction of G2/M arrest and apoptosis in human colon cancer cells. J Microbiol Biotechnol 19: 1482-1489, 2009.

48. Huang S, Pettaway CA, Uehara H, Bucana CD and Fidler IJ: Blockade of NF-kappaB activity in human prostate cancer cells is associated with suppression of angiogenesis, invasion, and metastasis. Oncogene 20: 4188-4197, 2001.

49. Lee SH, Lee CW, Lee JW, et al: Induction of apoptotic cell death by 2'-hydroxycinnamaldehyde is involved with ERK-dependent inactivation of NF-kappaB in TNF-alpha-treated SW620 colon cancer cells. Biochem Pharmacol 70: 1147-1157, 2005.

50. Saccani A, Schioppa T, Porta C, et al: p50 nuclear factor-kappaB overexpression in tumor-associated macrophages inhibits M1 inflammatory responses and antitumor resistance. Cancer Res 66: 11432-11440, 2006.

51. Tang X, Liu D, Shishodia S, et al: Nuclear factor-kappaB (NF-kappaB) is frequently expressed in lung cancer and preneoplastic lesions. Cancer 107: 2637-2646, 2006.

52. Hardwick JC, van den Brink GR, Offerhaus GJ, van Deventer SJ and Peppelenbosch MP: NF-kappaB, p38 MAPK and JNK are highly expressed and active in the stroma of human colonic adenomatous polyps. Oncogene 20: 819-827, 2001. 